\title{
A polypropylene mesh modified with poly- $\varepsilon$-caprolactone nanofibers in hernia repair: large animal experiment
}

This article was published in the following Dove Press journal: International Journal of Nanomedicine

\author{
Barbora East ${ }^{1,2}$ \\ Martin Plencner ${ }^{3,4}$ \\ Martin Kralovic ${ }^{1,3,5}$ \\ Michala Rampichova ${ }^{3}$ \\ Vera Sovkova ${ }^{1,3,5}$ \\ Karolina Vocetkova ${ }^{1,3,5}$ \\ Martin Otahal $\left.\right|^{6,7}$ \\ Zbynek Tonar ${ }^{8,9}$ \\ Yaroslav Kolinko, 8 \\ Evzen Amler ${ }^{1,3,5}$ \\ Jiri Hoch ${ }^{1,10}$
}

'Second Medical Faculty, Charles University in Prague, Prague, Czech Republic; ${ }^{2}$ Third Department of Surgery, Motol Faculty Hospital, First Medical Faculty, Charles University in Prague, Prague, Czech Republic; ${ }^{3}$ Institute of Experimental Medicine, The Czech Academy of

Sciences, Prague, Czech Republic; ${ }^{4}$ The Czech Academy of Sciences, Institute of Physiology, Prague, Czech Republic; ${ }^{5}$ University Centre of Energy Efficient Buildings, Czech Technical University in Prague, Bustehrad, Czech Republic; ${ }^{6}$ Department of Anatomy and Biomechanics, Faculty of Physical Education, Charles University in Prague, Prague, Czech Republic; ${ }^{7}$ Department of Natural Sciences, Faculty of Biomedical Engineering, Czech Technical University in Prague, Kladno, Czech Republic; ${ }^{8}$ Department of Histology and Embryology, ${ }^{9}$ Biomedical Centre, Faculty of Medicine in Pilsen, Charles University in Prague, Pilsen, Czech Republic; ${ }^{10}$ Surgery Department, Motol Faculty Hospital, Second Medical Faculty, Charles University in Prague, Prague, Czech Republic

Correspondence: Barbora East Third Department of Surgery, Motol Faculty Hospital, First Medical Faculty, Charles University in Prague, V Uvalu 84, 15006 Prague 5, Czech Republic Tel +420605342192

Fax +420224438003

Email barbora.east@gmail.com
Purpose: Incisional hernia repair is an unsuccessful field of surgery, with long-term recurrence rates reaching up to $50 \%$ regardless of technique or mesh material used. Various implants and their positioning within the abdominal wall pose numerous long-term complications that are difficult to treat due to their permanent nature and the chronic foreign body reaction they trigger. Materials mimicking the 3D structure of the extracellular matrix promote cell adhesion, proliferation, migration, and differentiation. Some electrospun nanofibrous scaffolds provide a topography of a natural extracellular matrix and are cost effective to manufacture.

Materials and methods: A composite scaffold that was assembled out of a standard polypropylene hernia mesh and poly- $\varepsilon$-caprolactone (PCL) nanofibers was tested in a large animal model (minipig), and the final scar tissue was subjected to histological and biomechanical testing to verify our in vitro results published previously.

Results: We have demonstrated that a layer of PCL nanofibers leads to tissue overgrowth and the formation of a thick fibrous plate around the implant. Collagen maturation is accelerated, and the final scar is more flexible and elastic than under a standard polypropylene mesh with less pronounced shrinkage observed. However, the samples with the composite scaffold were less resistant to distracting forces than when a standard mesh was used. We believe that the adverse effects could be caused due to the material assembly, as they do not comply with our previous results.

Conclusion: We believe that PCL nanofibers on their own can cause enough fibroplasia to be used as a separate material without the polypropylene base, thus avoiding potential adverse effects caused by any added substances.

Keywords: nanofibers, hernia, mesh, PCL, minipig, biomechanical, large animal

\section{Introduction}

Incisional hernia repair is a dark chapter of surgery as the long-term recurrence rates remain unacceptably high regardless of the techniques or materials used. ${ }^{1,2}$ Various mesh materials and positioning within the abdominal wall possess numerous long-term complications, mainly adhesion formation, delayed graft infection or rejection, fistula formation, and hernia recurrence. ${ }^{3}$ There are more than 100 surgical meshes currently available but the ideal mesh does not appear to exist yet., ${ }^{4,5}$

A material suitable to manufacture any implant must be biocompatible, should not cause a foreign body reaction, show adverse immune response, or be toxic or carcinogenic. It must be able to be sterilized without changing its properties. Today, we believe that the mechanical properties of the material are also very important. At the very least, it must withstand the implantation process and patient's postoperative 
activities. ${ }^{6}$ In addition, an optimal mesh should serve as a bioscaffold, promote healing, and minimize wound-related complications. A way to improve the biocompatibility of present surgical meshes is to combine them with scaffolds used in tissue engineering.

The extracellular matrix (ECM) is an important controller of cell adhesion, proliferation, migration, and differentiation. A structure of material that mimics the natural ECM could provide this special microenvironment suitable for cell adhesion, proliferation, and angiogenesis, thus, facilitating the formation of a mechanically reliable scar. Nanofibrous scaffolds used in tissue engineering meet these criteria by having a topography of the ECM and offering a high surfaceto-volume ratio, as well as having the presence of many interconnected pores and a possibility to modify their surface. ${ }^{7}$

The polyesters of the poly( $\alpha$-hydroxy acid) family are bioresorbable, and they are used in various medical applications. ${ }^{8}$ Poly- $\varepsilon$-caprolactone (PCL) is a US Food and Drug Administration approved, hydrophobic, and biodegradable semicrystalline aliphatic polyester with a low melting point. ${ }^{9,10}$ It was one of the first polymers synthesized in the 1930s but lost its popularity due to a long resorption time and intracellular resorption pathways. ${ }^{11}$ Its poor mechanical properties did not allow it to be used in high-load-bearing applications. PCL was forgotten by researches for many years but was rediscovered with the onset of tissue engineering due to its superior viscoelastic and rheological properties allowing it to be manufactured into large-scale scaffolds. ${ }^{12}$ Surprisingly, to this date, the exact in vivo degradation process and its time schedule are not fully understood, and the reported degradation time varies from months to years.

The idea to use electrospun nanofibers is not unique. ${ }^{13}$ However, commonly mentioned fibers are more on the microscale than the nanoscale and therefore pose different mechanical and biological properties. ${ }^{14,15}$ In a recent study, we have developed a composite PCL nanofiber-polypropylene (PCL/PP) mesh and evaluated the benefit of the PCL nanofiber mesh in vitro as well as in vivo in hernia surgery with positive results. ${ }^{16}$ The purpose of this study is to verify and obtain more complex results in laboratory minipig, a large animal with an abdominal wall thickness comparable to that of humans.

\section{Materials and methods Scaffold preparation}

PCL nanofibers were prepared by an electrospinning method from PCL prepared under Good Manufacturing Practice with an inherent viscosity midpoint of $1.2 \mathrm{dL} / \mathrm{g}$ (Purasorb ${ }^{\circledR}$ PC 12; Corbion Purac, Gorinchem, the Netherlands;
Lukas et $\mathrm{al}^{32}$ ). Electrospinning was performed from a $16 \mathrm{wt} \%$ solution of PCL dissolved in chloroform:ethanol with a ratio of 9:1. A high-voltage source generated voltages of up to $50 \mathrm{kV}$, and the polymer solution was connected to a high-voltage source. Electrospun nanofibers were deposited on the grounded collecting electrode. The PCL nanofibers had a surface density of $25.2 \mathrm{~g} / \mathrm{m}^{2}$. For the attachment of the PCL nanofibers onto a PP surgical mesh (Prolene ${ }^{\mathrm{TM}}$; Ethicon Inc., Somerville, NJ, USA), a $32 \mathrm{wt} \%$ solution of PCL dissolved in chloroform was used. The PCL glue at the density of $44 \mathrm{~g} / \mathrm{m}^{2}$ was deposited on the PP mesh using a Teflon cylinder, and the PCL nanofibers were transferred onto that surface. For the in vivo experiment, the PP meshes coated with PCL nanofibers were cut into rectangular shapes with 4 and $7 \mathrm{~cm}$ sides and, for the in vitro into round patches with $6 \mathrm{~mm}$ in diameter. The scaffolds were sterilized using ethylene oxide at $37^{\circ} \mathrm{C}$ and used 1 week after sterilization, in order to air out possible remnants of the ethylene oxide.

\section{In vitro analysis}

\section{Scaffold seeding and cell culture}

The sterile PP mesh, composite scaffolds composed of polypropylene mesh/PCL (PP/PCL) nanofibrous scaffolds, and PCL nanofibrous scaffolds were seeded with 3T3-A21 fibroblasts at a cell density of 14,200 cells $/ \mathrm{cm}^{2}$. A murine 3T3-A21 cell line (fibroblasts) was purchased from SigmaAldrich (St Louis, MO, USA). The cells were cultured in DMEM (Sigma-Aldrich), supplemented with 10\% fetal bovine serum (Thermo Fisher Scientific, Waltham, MA, USA), and treated with penicillin/streptomycin (100 IU/mL and $100 \mu \mathrm{g} / \mathrm{mL}$, respectively, Sigma-Aldrich). The medium was refreshed every 3-4 days.

\section{Cell metabolic activity}

To determine the metabolic activity, MTS test (CellTiter96 ${ }^{\circledR}$ AQueous One Solution Cell Proliferation Assay; Promega Corporation, Madison, WI, USA) was used. On days 1, 3, 7 , and 14 of the experiment, the scaffolds with adhered cells were transferred into new wells. To each scaffold, $20 \mu \mathrm{L}$ of MTS solution and $100 \mu \mathrm{L}$ of fresh medium were added. After incubation $\left(37^{\circ} \mathrm{C}, 10 \% \mathrm{CO}_{2}\right)$, the results were examined by spectrophotometry in an absorbance microplate reader (ELx800; BioTek, Winooski, VT, USA) at $490 \mathrm{~nm}$ (reference wavelength $690 \mathrm{~nm}$ ). The absorbance of a medium without cells was subtracted from the measured data.

\section{Cell proliferation}

To determine the cell proliferation, a fluorescence-based kit Quant-iT ${ }^{\text {TM }}$ PicoGreen ${ }^{\circledR}$ dsDNA Assay Kit (Thermo 
Fisher Scientific) was used on days 1, 3, 7, and 14 of the experiment. The samples were transferred into tubes containing $200 \mu \mathrm{L}$ of a cell lysis buffer $(10 \mathrm{mM}$ Tris, $1 \mathrm{mM}$ EDTA, $0.2 \% \mathrm{v} / \mathrm{v}$ Triton X-100). The samples underwent three freeze/thaw cycles; in between the cycles, the samples were vortexed. To quantify the DNA content of the cells cultivated on the scaffolds, a standard curve was prepared using samples with a known concentration of $\lambda$ DNA. The DNA content was determined by mixing $100 \mu \mathrm{L}$ PicoGreen reagent and $100 \mu \mathrm{L}$ of the DNA sample. The samples were loaded in triplicate, and the florescence intensity was measured on a multimode microplate reader (Synergy HT; BioTek; $\lambda_{\mathrm{ex}}=480-500 \mathrm{~nm}, \lambda_{\mathrm{em}}=520-540 \mathrm{~nm}$ ).

\section{Cell visualization via scanning electron microscopy (SEM)} To visualize the cells adhered on the scaffolds, SEM was used on day 14 . The samples were fixed with $2.5 \%$ glutaraldehyde (Sigma-Aldrich) at $4^{\circ} \mathrm{C}$. After $2 \mathrm{~h}$, the samples were dehydrated with ethanol changes $(35 \%, 48 \%, 70 \%$, 96\%, and 100\%). Hexamethyldisilazane (Sigma-Aldrich) was used to remove any residual water from the samples. The samples were sputter-coated with gold $(\sim 30 \mathrm{~nm})$ and visualized using a Vega 3 SBU microscope (Tescan, Brno, Czech Republic).

\section{Cell visualization via confocal microscopy}

On days 1, 7, and 14, the cells seeded on the scaffolds were fixed with methanol $\left(-20^{\circ} \mathrm{C}\right)$, washed with $\mathrm{PBS}$, and stained with DiOC6 ( $1 \mu \mathrm{g} / \mathrm{mL}$ in PBS; $30 \mathrm{~min}$ at RT; green color, wavelength maxima $\lambda_{\text {ex }}=488 \mathrm{~nm}, \lambda_{\mathrm{em}}=501 \mathrm{~nm}$; Thermo Fisher Scientific) to visualize the cell membranes and with propidium iodide $(5 \mu \mathrm{L} / \mathrm{mL}$ in PBS; $10 \mathrm{~min}$ at RT; red color, wavelength maxima $\lambda_{\mathrm{ex}}=536 \mathrm{~nm}, \lambda_{\mathrm{em}}=617 \mathrm{~nm}$ ) to visualize the cell nuclei. The samples were scanned using LSM 510 DUO confocal microscope (Zeiss, Oberkochen, Germany).

\section{Statistical analysis}

The data were statistically evaluated using SigmaStat 3.5 software. Statistical significance between a pair of groups was determined using analysis of variance testing. Dunn's test and Bonferroni correction were used for post hoc analysis. The data are presented as mean values $\pm \mathrm{SD}$. A value of $p<0.05$ was considered statistically significant.

\section{In vivo experiment}

Experimental animals, surgical procedure, and postoperative care

A total of seven minipigs (female, weight $40-55 \mathrm{~kg}$ ) were obtained from a conventional breed (Institute of Animal
Physiology and Genetics AS CR, v.v.i., Libechov, Czech Republic) and bred at the Department of diseases of ruminants and pigs in the rooms of the Experimental department with a certified stable environment (temperature and air moisture). They were fed ad libitum using the standard pig diet and had unlimited access to water.

Ethical principles and guidelines for scientific experiments on animals were respected throughout this study. The maintenance and handling of the experimental animals followed EU Council Directive 86/609 EEC, and the animals were treated in accordance with the principles of care and use of animals (Decree no. 419/2012 Coll). The investigation was approved by the Expert Committee of the Faculty of Veterinary Medicine at the University of Veterinary and Pharmaceutical Sciences, Brno, Czech Republic (protocol number 34-2016) and conformed to Czech Animal Protection Law 246/92.

After 10 days of acclimatization, the animals were prepared for surgery. All of the animals were premedicated with a combination of tiletamine, zolazepam (2 mg/kg, Zoletil 100; Virbac Corporation, Fort Worth, TX, USA), ketamine (2 mg/kg, Narketan; Vetoquinol UK Limited, Buckingham, UK), and xylazin (2 mg/kg; Rometar-Bioveta Inc., Ivanovice na Hane, Czech Republic) intramuscularly (im). The lateral auricular vein was cannulated afterward, and general anesthesia was induced with a propofol (1-2 mg/kg intravenous [iv]; Norofol, Norbrook, Newry, UK) followed by a tracheal intubation. A total intravenous anesthesia was maintained afterward with propofol ( $0.1-0.3 \mathrm{mg} / \mathrm{kg} / \mathrm{h}$ iv; Fresenius, Bad Homburg, Germany).

Following completion of all the preoperative preparations, the animals were placed in the dorsal position and a full thickness skin incision of $20 \mathrm{~cm}$ in length was made in the midline of the abdomen starting $3 \mathrm{~cm}$ below the xiphoid. Two separate $5 \mathrm{~cm}$ long incisions were made in the linea alba and closed with a running suture (PDS, 3.5M, Ethicon Inc.). Both defects were subsequently reinforced with a randomly chosen implant (Prolene mesh [Ethicon Inc.] or Composite mesh) and fixated to the fascia with a running suture $5 \mathrm{~mm}$ from the edge of the implant and to the suture line (PDS 3M). Subcutaneous tissue and skin were also closed using a running suture (Ethilon 3M; Ethicon Inc.). During surgery, the animals were placed on a heating pad and were hydrated intravenously.

A dose of antibiotic $(20 \mathrm{mg} / \mathrm{kg}$ im, Amoxicillinum Acidum clavulanicum for veterinary use, Synulox; Pfizer, Inc., New York, NY, USA) was administered to each animal $30 \mathrm{~min}$ before surgery followed by a dose of $8.75 \mathrm{mg} / \mathrm{kg}$ im for the next 7 days. All animals were given a single dose of meloxicam analgesic $(0.4 \mathrm{mg} / \mathrm{kg}$ im, Metacam $20 \mathrm{mg} / \mathrm{mL}$; 
Boehringer Ingelheim, Ingelheim, Germany) on the first day after surgery. The pigs were not limited in their movement after surgery.

All the animals were sacrificed using an iv thiopental (Valeant Pharmaceuticals, Laval, QC, Canada) and embutramide-mebezonium iodide-tetracaine hydrochloridedimethylformamide (T-61; Merck \& Co., Inc., Whitehouse Station, NJ, USA) overdose 6 weeks later. Samples removed for histological and immunohistochemical analyses were photographed, harvested, and fixed in 10\% phosphate-buffered formalin for $48 \mathrm{~h}$. Two samples of $1 \times 6 \mathrm{~cm}$ of full-layer abdominal wall with mesh were removed for biomechanical testing (Figure 1).

\section{Histological analysis}

Fourteen samples were fixed with formaldehyde and embedded into paraffin blocks. The samples included the incision line (marked with a stitching material) and $20 \mathrm{~mm}$ of surrounding abdominal wall tissue. The paraffin blocks were processed by a standard technique, and at least 10 histological sections $5-\mu \mathrm{m}$ thick were obtained from each block. Two sections were stained with hematoxylin-eosin (to visualize inflammatory infiltrate), two with a Verhoeff's hematoxylin and a green trichrome (to differentiate collagen, fat, and muscle tissue and inflammatory infiltrate), and two with a picrosirius red (to distinguish collagen I fibrils in a polarized light microscopy). ${ }^{17}$ Another two sections were used to prove smooth muscle cell actin in larger microvessels (not capillaries) and contractile myofibroblasts (Antibody 1A4; DakoCytomation, Glostrup, Denmark), visualization by immunoperoxidase reaction using N-Histofine kit (Nichirei Biosciences, Tokyo, Japan) and diaminobenzidin (Fluka, Buchs, Switzerland). The background was stained with Gill's hematoxylin. The last two sections were stained (following a 20 -min pretreatment at $96^{\circ} \mathrm{C}$ treatment in Dako Target Retrieval Solution, pH 9) using a CD31 antibody (clone J70A, dilution 1:40; Dako Denmark A/S Cytomation, Glostrup, Denmark) for detection of vascular endothelium (Figure 2).

A quantitative analysis of the histological samples was conducted using stereological point grid and counting frame implemented in the newCAST ${ }^{\mathrm{TM}}$ program (Visiopharm, Hørsholm, Denmark). Six variables were used for the quantitative description of the samples, both at the suture line and in the adjacent tissue (Table 1).

\section{Statistical analysis}

The primary data were processed with a Statistica Base 10 (StatSoft, Inc., Tulsa, OK, USA) software. Statistical
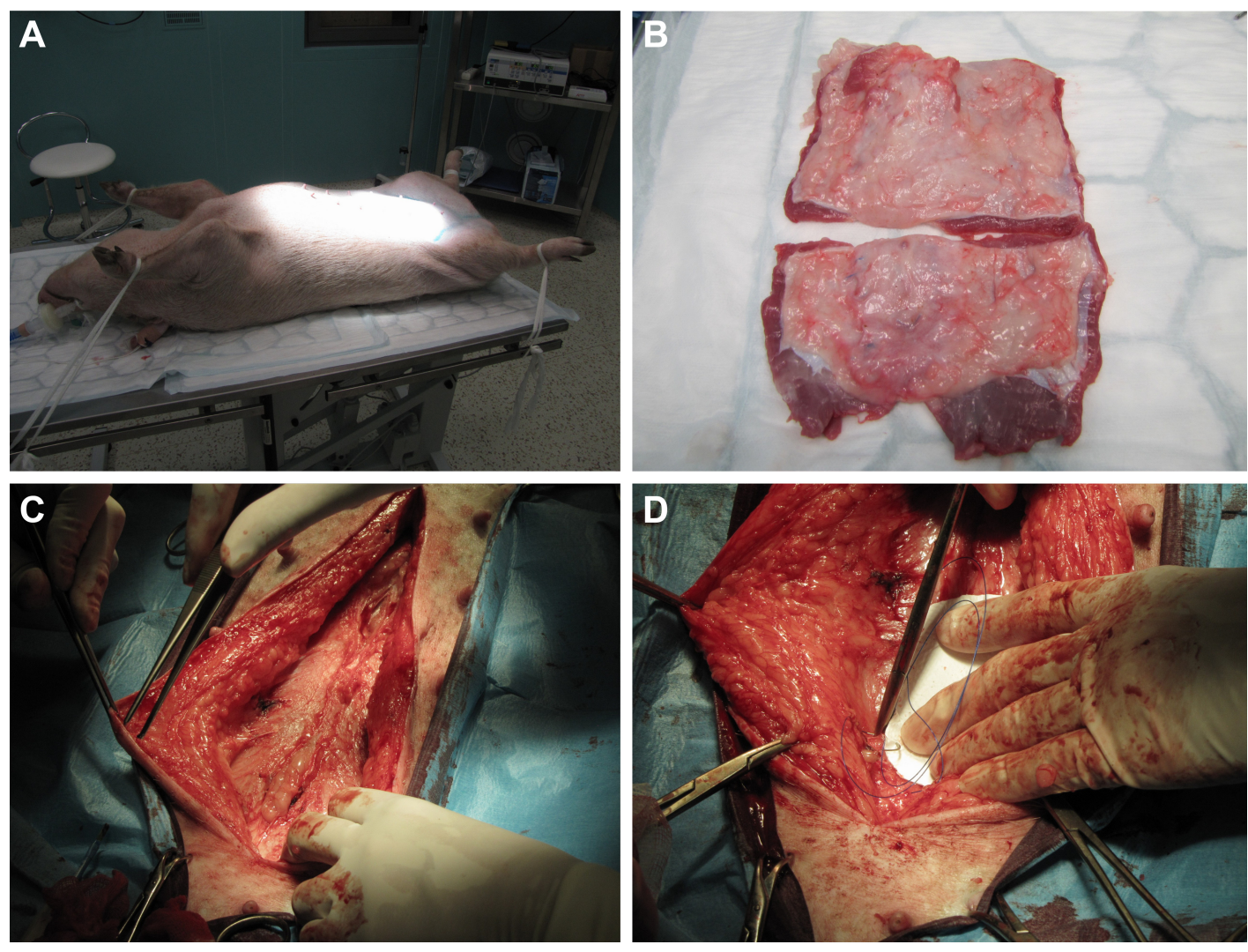

Figure I Surgical procedure, mesh positioning, and sample harvesting.

Note: (A) Position of the experimental animal during the surgery; (B) harvested sample of the abdominal wall; (C) suture of the laparotomy; (D) mesh fixation. 

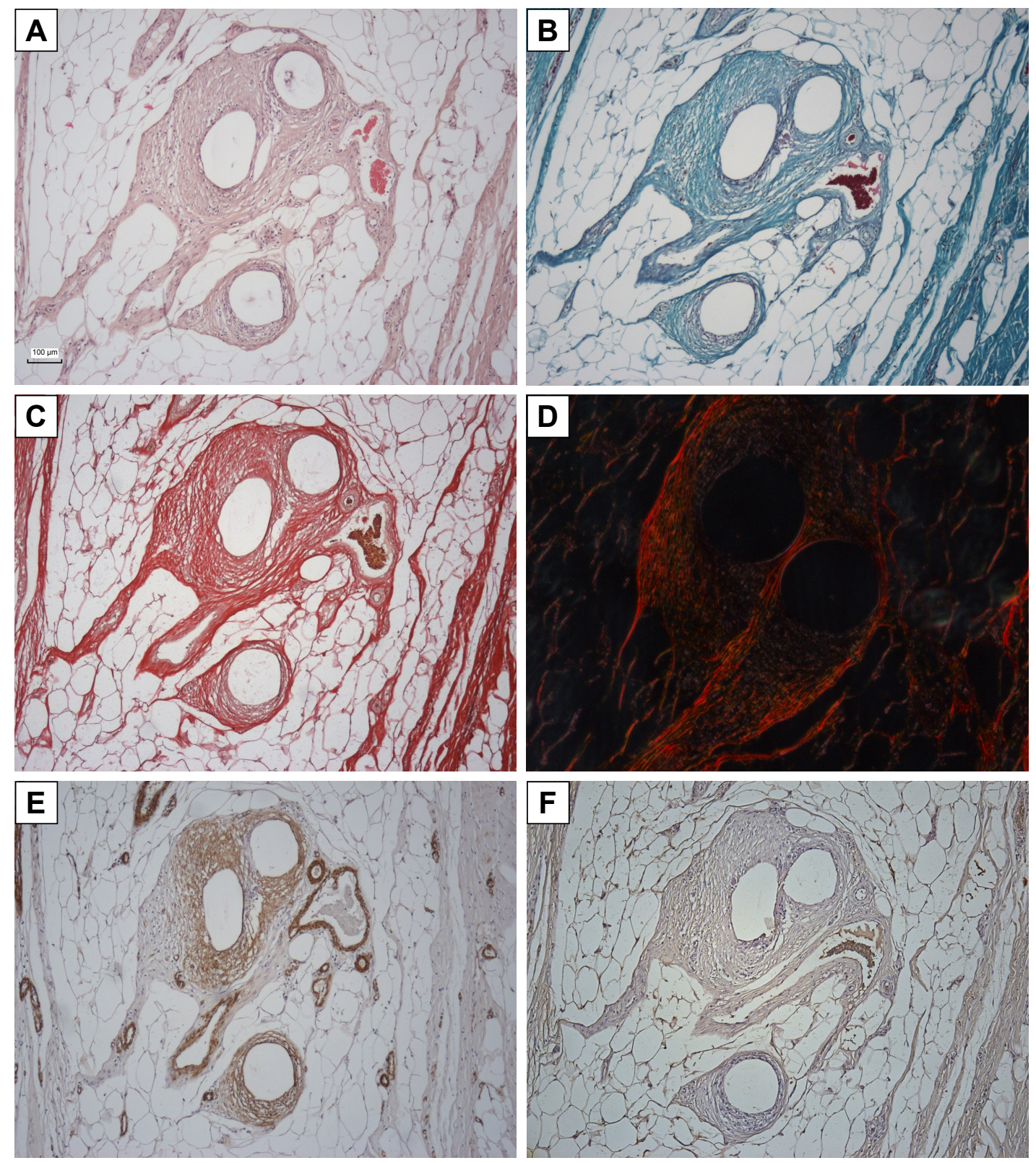

Figure 2 An overview of the staining applied at corresponding areas of histological sections.

Notes: (A) Hematoxylin-eosin; (B) Verhoeff's hematoxylin and green trichrome; (C) picrosirius red in a bright-field microscope; (D) picrosirius red in a circularly polarized light; (E) antibody against smooth muscle actin (myofibroblasts and smooth muscle cells in a vascular wall); (F) CD3I antibody (endothelium of microvessels). Scale bar: I00 $\mu$ m.

Table I Morphometric parameters used for quantitative histology

\begin{tabular}{llll}
\hline $\begin{array}{l}\text { Quantitative } \\
\text { parameter }\end{array}$ & $\begin{array}{l}\text { Objective } \\
\text { used }\end{array}$ & $\begin{array}{l}\text { Image } \\
\text { fields }\end{array}$ & Biological significance \\
\hline$A_{A}$ (collagen I, incision) & $10 \times$ & 4 & $\begin{array}{l}\text { Higher content of matured collagen I fibrils } \\
\text { contributes to a mechanical strength of a scar. } \\
A_{A} \text { (collagen I, no incision) }\end{array}$ \\
$A_{A}$ (actin, incision) & $10 \times$ & 4 & Higher amount of contractile myofibroblasts \\
$A_{A}$ (actin, no incision) & contributes to the constriction of the scar. \\
$Q_{A}$ (microvessels, incision) & $10 \times$ & 4 & Higher density of blood vessels is likely to promote \\
$Q_{A}$ (microvessels, no incision) & & growth and trophic status of the healing tissue. \\
\hline
\end{tabular}

Notes: $A_{A}$ (area per area) stands for an area fraction (area per area) of the component (collagen I fibrils or actin-positive myofibroblasts) in the reference area of the incision (incision) or adjacent tissue (no incision; $20 \mathrm{~mm}$ from incision laterally). Area fractions were assessed using stereological point grid. $Q_{\mathrm{A}}$ (quantity per area) is the number of SMA profiles or CD3I-positive profiles of microvessels per unit area estimated using an unbiased counting frame. ${ }^{18} \mathrm{~A}$ reference space was chosen to be the connective tissue under the dermis surrounding abdominal fascia. The quantitative histological design is comparable to our previous study. ${ }^{16}$ Abbreviation: SMA, smooth muscle actin positive. 
correlation of variables was assessed using Spearman's correlation coefficient. The Mann-Whitney $U$-test was used to test the consistency of population medians between groups. A pair of samples from the same incision and non-incision sampling points was compared by a Wilcoxon pair test. Only results with $p<0.05$ are presented in the Results section.

\section{Biomechanical testing}

The maximum tensile strength, Young's modulus, and yield stress were determined on a Micro tester digital tension meter (as described earlier). ${ }^{16}$ The force response of each sample was detected at the grips of the tension meters during the entire cycle. Mechanical properties of each of the samples were analyzed. The following quantities were measured: elasticity in tension $E(\mathrm{MPa})$, maximum stress $\sigma_{\max }(\mathrm{MPa})$ and the corresponding maximal specific elongation $\varepsilon_{\text {max }}(-)$, as well as Yield stress $\sigma_{\mathrm{k}}(\mathrm{MPa})$ and corresponding yield specific elongation $\varepsilon_{\mathrm{k}}(-)$. The structure of each sample and the character of the tear line were scanned throughout the experiment by an Olympus SZX-12 microscope equipped with an ultrasensitive PCO Sensicam video camera (Olympus Corporation, Tokyo, Japan). The tissue samples $(9.4 \times 25 \times 51.5 \mathrm{~mm}$ on average strips of regenerated abdominal wall) were individually attached to the grips of the Micro tester (Figure 3) in a longitudinal manner adjacent to the mesh. (The device was developed in Department of Anatomy and Biomechanics, Faculty of Physical Education and Sport, Charles University in Prague, Utility model with document/registration number 25008, Industrial Property Office, Czech Republic. $)^{16}$ The samples were stretched by $5 \mathrm{~mm}$ at a speed of $10 \mathrm{~mm} / \mathrm{s} 10$ times and were then pulled at a speed of $0.5 \mathrm{~mm} / \mathrm{s}$ until the sample failed. ${ }^{16}$

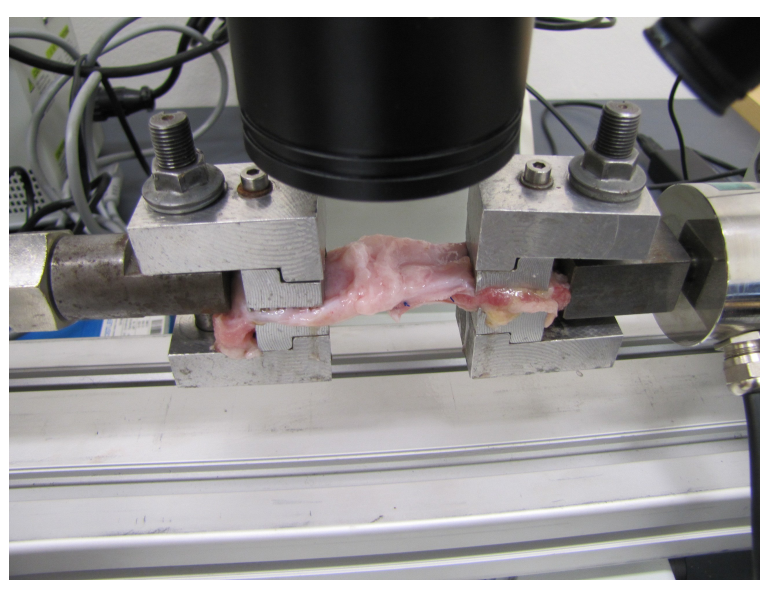

Figure 3 Micro tester digital tension meter.

Note: The sample is attached to the tension meter branches adjacent to the edge of the mesh.

\section{Results}

In vitro

To assess the suitability of the composite scaffolds, the prepared samples were tested in vitro. To test the biocompatibility of the prepared scaffolds, an MTS test and proliferation assay test were used. The tested groups contained PP mesh, PP/PCL, and the PCL nanofibers.

On days 1, 3, 7, and 14, the MTS test was conducted to determine cell metabolic activity (Figure 4A). Acquired data demonstrated that all the tested samples (PP, PP/PCL, and $\mathrm{PCL})$ are biocompatible, as increasing metabolic activity was seen throughout the experiment. However, throughout the whole experiment, metabolic activity of cells seeded on the PCL nanofibrous scaffold was significantly higher when compared with metabolic activity of cells seeded on the PP mesh. A statistically significant increase in cell metabolic activity on the PP/PCL composite scaffold was observed on day 14 of the experiment.

A similar pattern was observed in the proliferation PicoGreen assay (Figure 4B). The DNA amount contained in the cells seeded on the scaffolds was determined on respective days. Significant differences were observed from day 7 of the experiment on the sample containing nanofibers (PP/ PCL, PCL) when compared with the PP mesh.

The morphology of the seeded cells was visualized using SEM and confocal microscopy. Confocal microscopy images (Figure 5A) of the PP/CL and PCL samples showed better initial adhesion and, subsequently, improved proliferation rate of fibroblasts. Fibroblasts seeded on the PP mesh were not evenly distributed and formed clusters. An SEM was performed to visualize the scaffold and cell morphology (Figure 5B). The images showed subconfluent layers on the nanofiber-containing scaffolds in contrast to the PP mesh where the cells were well spread, but very scarce due to its low surface-to-volume ratio.

\section{In vivo}

\section{Clinical postoperative course}

We did not observe any obvious changes of condition or weight loss for any animal. A macroscopic evaluation of samples from all groups was made after removal of the abdominal wall. The surface of the regenerated tissue showed no signs of inflammation or infection in any groups. One animal suffered a hernia in-between the two implants.

Macroscopic analysis revealed rather disappointing results when a standard PP mesh was integrated in the abdominal wall, while the composite material led to the formation of a thick plate with profuse fibroplasia. 


\section{A Metabolic activity of fibroblasts}

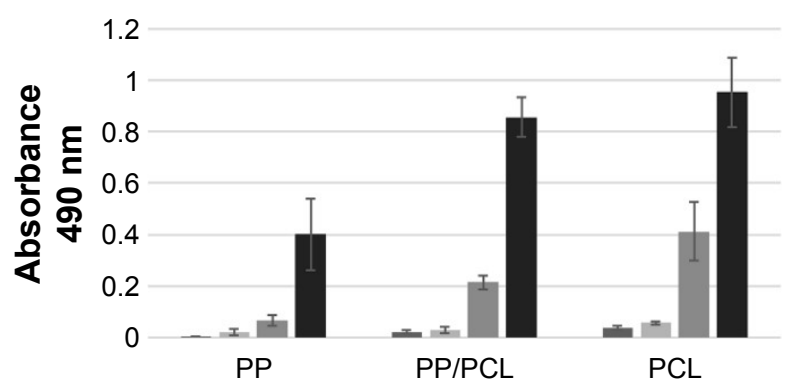

B

\section{Proliferation of fibroblast}

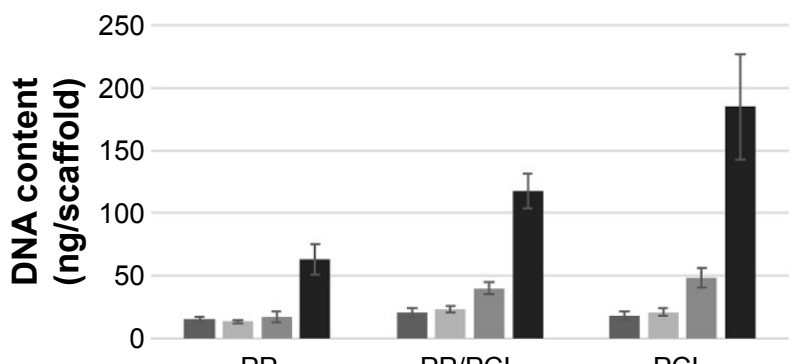

PP

PP/PCL

PCL

\begin{tabular}{l|l|l|l} 
Day 1 & Day 3 & Day 7 & Day 14
\end{tabular}

Figure 4 Metabolic activity and proliferation of the seeded fibroblasts on days I, 3, 7, and I4.

Notes: (A) Metabolic activity of fibroblasts determined using MTS assay. (B) Proliferation of fibroblasts determined using PicoGreen ${ }^{\circledR}$ assay. Statistical significance was set at $p<0.05$.

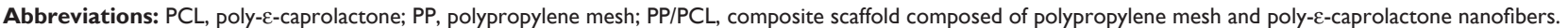

\section{Histological analysis}

All the samples contained a layer of subcutaneous fat, abdominal muscles with their fascias and aponeuroses, extraperitoneal fat, and a layer of parietal peritoneum. Deeper layers of abdominal fascia contained residues of elastic fibers. The incision lines were connected in one layer of healing tissue; however, abdominal muscles retained their layered organization.
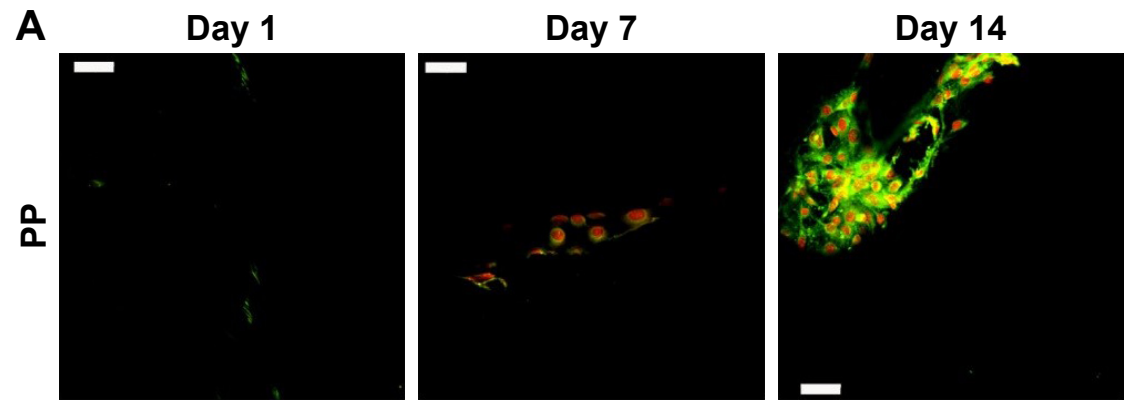

B
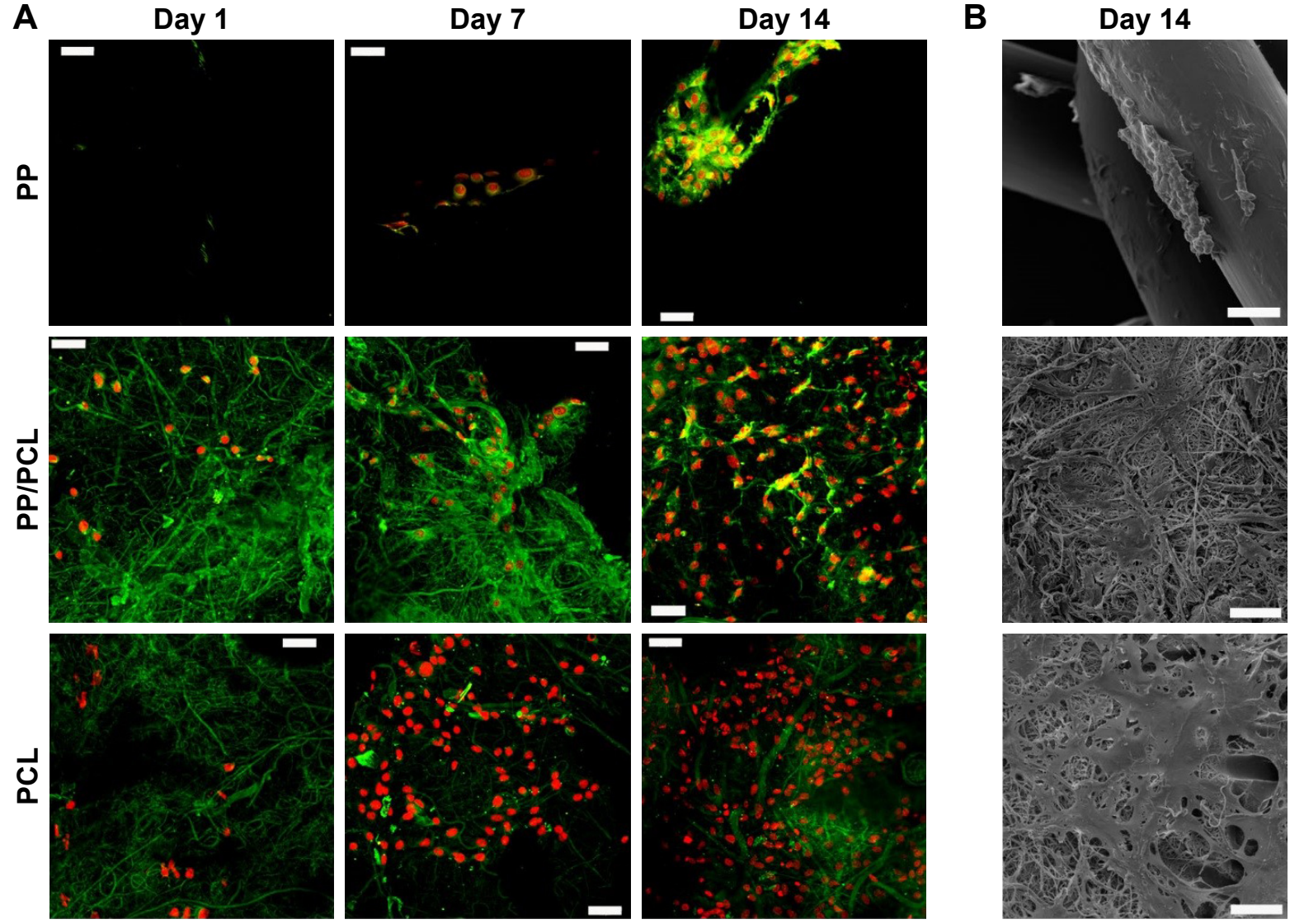

Figure 5 Visualization of fibroblasts seeded on scaffolds.

Notes: (A) Confocal microscopy images on days I, 7, and 14. Green color depicts cellular biomembranes and red color cell nuclei. Magnification $200 \times$, scale bars $50 \mu \mathrm{m}$. (B) Scanning electron images on day 14. Magnification 650x, scale bars $50 \mu \mathrm{m}$.

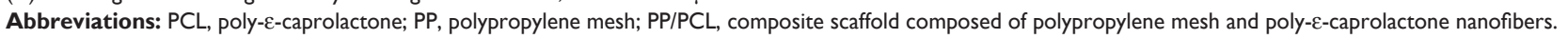



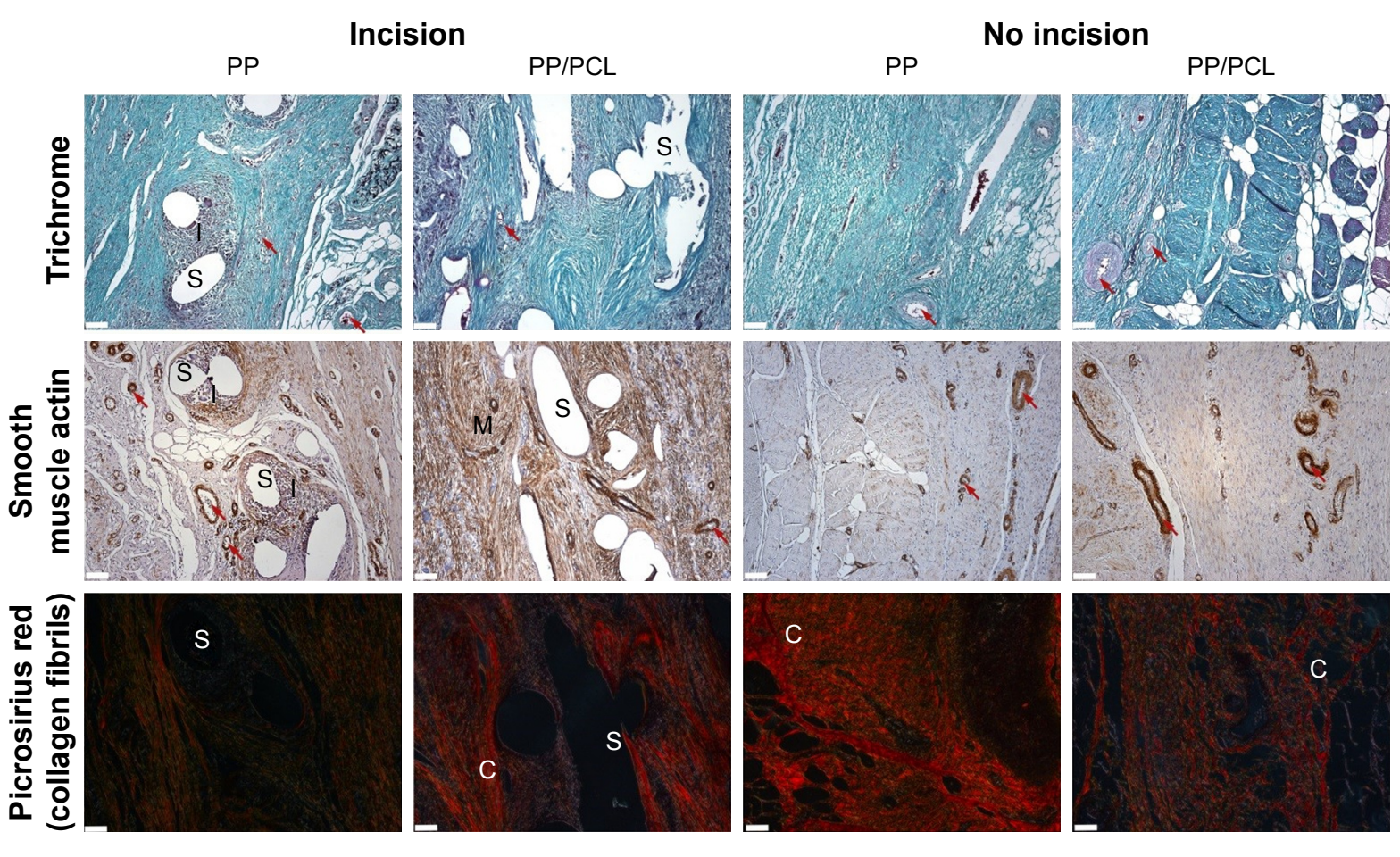

Figure 6 Typical histological findings in the "incision" and "no incision" areas.

Notes: The stitches (S) of PP samples were surrounded by the infiltrated with inflammatory cells (I). The PP/PCL sample contains a smaller number of actin-positive vessels (red arrows), greater fraction of actin-positive myofibroblasts (M) and collagen type I (C) at the incision areas. Magnification I0X, scale bars I00 $\mu \mathrm{m}$.

Abbreviations: PCL, poly- $\varepsilon$-caprolactone; PP, polypropylene mesh; PP/PCL, composite scaffold composed of polypropylene mesh and poly- $\varepsilon$-caprolactone nanofibers.

All the samples were compared separately in the "incision" and "non-incision" areas. Typical histological findings are shown in Figure 6. The sensitivity of the CD31 immunoreaction to detect the vascular endothelium was very variable; therefore, we have decided to use a more reliable number of microvessel profiles per unit area for the statistical analysis. All of the samples were compared separately in the "incision" and "non-incision" areas.

The primary data of quantitative analysis of the histological sections are present in Table S1 and represented in Figure 7. The incision area of the Composite group contained a greater area fraction of actin-positive myofibroblasts than the Prolene group (Mann-Whitney $U$-test: $p=0.002$; Figure 7C). The density of the microvessel profiles within the healing incision was greater in the Prolene group than in the Composite group (Mann-Whitney $U$-test: $p=0.018$; Figure 7E).

We have also observed that the Composite implant led to a scar formation with a higher content of actin-positive myofibroblasts but lower density of actin-positive microvessels in the "incision" compared with the "non-incision" area (Wilcoxon paired test: $p=0.017$ ). No statistically significant difference between the incision and the adjacent area without incision was observed in the scar tissue under the Prolene implant.

The "incision" area under the Composite implant contained a greater fraction of myofibroblasts but less microvessels than under the Prolene mesh. The amount of collagen type I depended more on the total amount of the myofibroblasts in the Prolene group.

Besides a number of others correlations (Table S1), a correlation analysis has shown that under the Prolene mesh, the collagen type I content within the incision had a moderate positive correlation with the fraction of actin-positive myofibroblasts (Spearman $R=0.54, p<0.05$ ), and the fraction of actin-positive myofibroblasts was moderately statistically linked with a greater density of both actin-positive and CD31positive microvessels $(R=0.60, p<0.05)$. Under the Composite meshes, the fraction of type I collagen was positively correlated weakly with the density of actin-positive microvessels $(R=0.40, p<0.05)$, but moderately with the density of CD31-positive microvessels $(R=0.57, p<0.05)$. The composite material was less infiltrated with inflammatory cells than the polypropylene implant, collagen fibrils were more aligned, and the scar contained less fat tissue (Figure 6), though these observations did not reach statistical significance. 

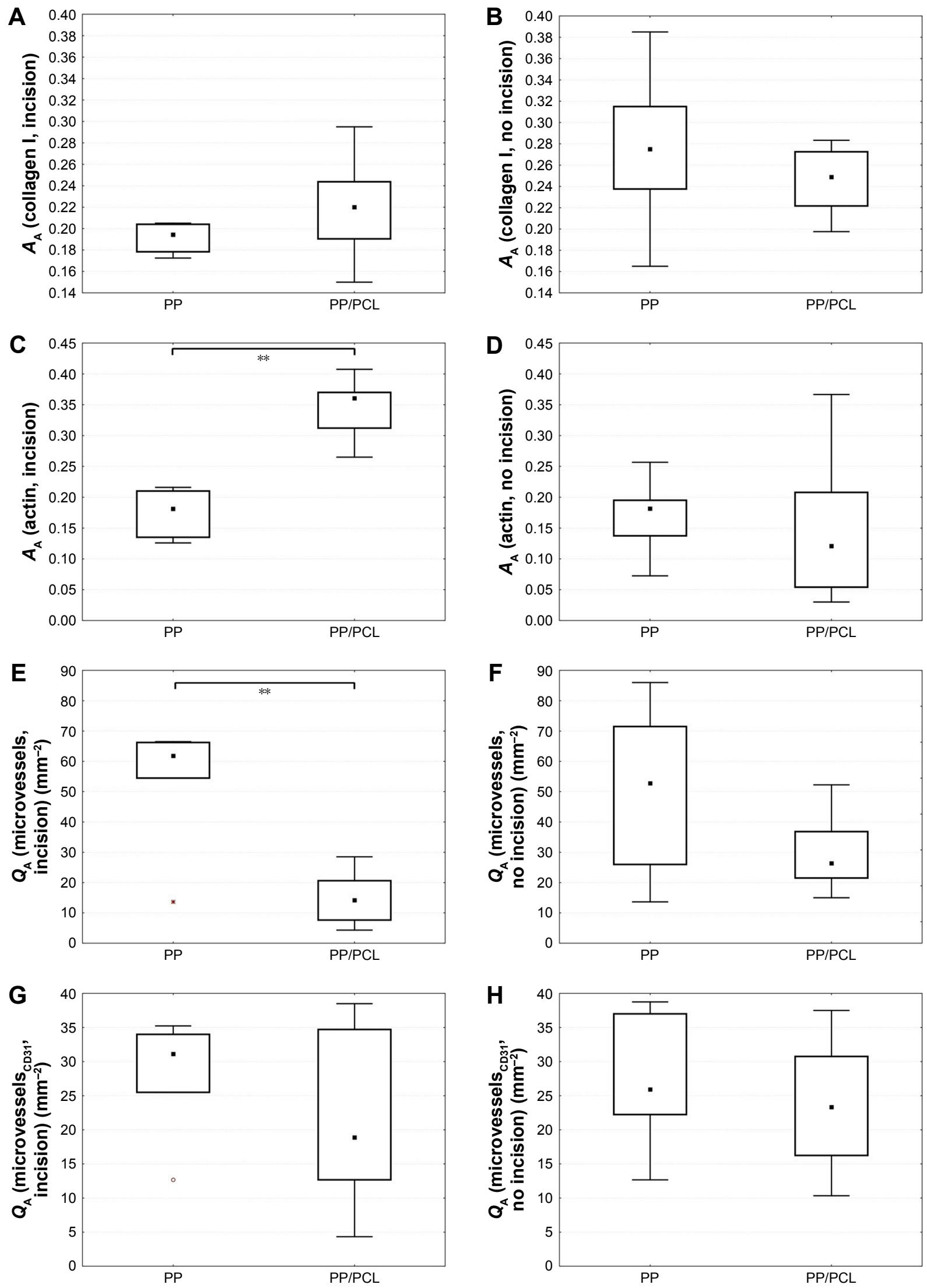

Figure 7 Comparing quantitative parameters of experimental groups (PP vs PP/PCL) in incision (A, C, E, and $\mathbf{G})$ and no incision (B, D, F, and $\mathbf{H})$.

Note: Corresponding compartments between groups were compared using the Mann-Whitney U-test (significant results are presented within the diagrams: $* * p<0.0 \mathrm{I})$.

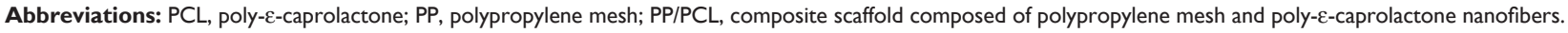


Table 2 Values of monitored parameters medians and SDs

\begin{tabular}{llllll}
\hline & $\mathrm{E}(\mathrm{MPa})$ & $\sigma_{\mathrm{k}}(\mathrm{MPa})$ & $\sigma_{\max }(\mathrm{MPa})$ & $\varepsilon_{\mathrm{k}}(-)$ & $\varepsilon_{\max }(-)$ \\
\hline $\mathrm{PP} / \mathrm{PCL}$ & $2.041 \pm 1.041$ & $0.314 \pm 0.213$ & $0.517 \pm 0.202$ & $0.262 \pm 0.091$ & $0.476 \pm 0.088$ \\
$\mathrm{PP}$ & $4.052 \pm 1.347$ & $0.750 \pm 0.233$ & $0.841 \pm 0.272$ & $0.239 \pm 0.051$ & $0.325 \pm 0.057$ \\
\hline
\end{tabular}

Abbreviations: PP, polypropylene mesh; PP/PCL, composite scaffold composed of polypropylene mesh and poly- $\varepsilon$-caprolactone nanofibers.

\section{Biomechanical analysis}

The measured data were processed and the values $\sigma_{\mathrm{k}}, \sigma_{\max }$, and $\mathrm{E}$ were calculated. As additional parameters, the relative elongation values corresponding to the monitored tension were determined. Table 2 lists values of monitored parameters medians and SDs. Comparison of monitored parameters of both groups is shown in Figure 8 .

The biomechanical testing shows that the Composite material leads to a scar formation with lower values measured in all monitored parameters, especially the Young's modulus (elasticity, E) and the yield strength $\left(\sigma_{\mathrm{k}}\right)$. The yield strength is a value determining the tension under which the deformation is still reversible. Under this value, there are no irreversible structural changes in the tissue. Young's modulus shows a linear correlation between the tension and deformation. In other words, the higher the value of Young's modulus, the tissue becomes stiffer and less flexible. Therefore, the Composite group is more flexible than the Prolene group to the detriment of a lower tensile strength.

\section{Discussion}

The idea to use nanofibrous electrospun implants in hernia surgery is neither new nor unique with various outcomes. ${ }^{19}$ There is an extensive search for a better material as meshes currently used show a high number of graft-related complications with a varying degree of severity and difficulty to treat. ${ }^{4,20}$ Electrospun nanofibrous materials used in tissue engineering with an ECM-like structure seem to be a suitable alternative. The ideal material should be synthetic, resorbable, and potentially bioactive. Compared with allografts and especially xenografts, synthetic materials are cheaper to produce and do not pose a risk of prion infection. Resorbable implants are fully degraded over time not maintaining a chronic inflammatory foreign body reaction, and all of its related complications. The ideal material should be replaced with the patient's own tissue with functional properties similar to the one that was lost. ${ }^{21}$

Electrospinning is the most popular and preferred technique for nanofiber fabrication as it is simple, cost effective, flexible, and able to be spun into a wide range of polymers. ${ }^{22}$ PCL nanofibers, despite its hydrophobicity, support the viability and metabolic activity of various cells - fibroblasts, chondrocytes, and mesenchymal stem cells. ${ }^{23,24}$ It could be explained by the profound protein deposition turning the surface to a hydrophilic environment. ${ }^{12}$ They are very slowly resorbable and cause a macrophage infiltration that should not be mistaken for a chronic body reaction typically seen around PP fibers. There are reports which mention that various sterilization techniques can modify fiber properties. ${ }^{25} \mathrm{We}$ have used ethylene oxide to sterilize our scaffolds not taking into consideration the possible changes in the mechanical stability of these fibers or potential residue of toxic ethylene oxide in the implants. ${ }^{26,27}$

Several studies have been conducted testing only the "in vitro" biocompatibility or biomechanical properties of nanofibrous scaffolds. ${ }^{14,28}$ The main aim of this study was to verify our previous results in a larger animal model. We have tested a composite PP + PCL mesh with mechanical properties of a standard surgical mesh and improved the biocompatibility thanks to the nanofibrous layer ${ }^{24}$ Compared to our previous study, we have changed the method of attaching the nanofibrous layer to the PP mesh. Therefore, we have repeated the "in vitro" part of the experiment to verify that it has no effect on the adhesion and proliferation of fibroblasts. However, we suspect that the way of connection of the two materials was responsible for some differences in the in vivo part of the experiment when comparing with our earlier studies. Previously, we have electrospun the fibers straight on the PP mesh but this time we have used a special PCL/chloroform glue with almost double the PCL content of the nanofibrous layer alone. Just as published before, even this time the proliferation test has proven an increased biocompatibility of the Composite implant by day 14 of the experiment with a statistical significance. ${ }^{24}$ Confocal microscopy images also revealed a better initial adhesion of fibroblasts as fibroblasts seeded on the PP mesh were not evenly distributed and formed clusters. Importantly, the metabolic activity of fibroblasts was significantly higher on the Composite scaffold compared with PP mesh throughout the whole experiment.

Prosthetic materials based on PP, which are most widely used, induce a rapid acute inflammatory response followed 
A

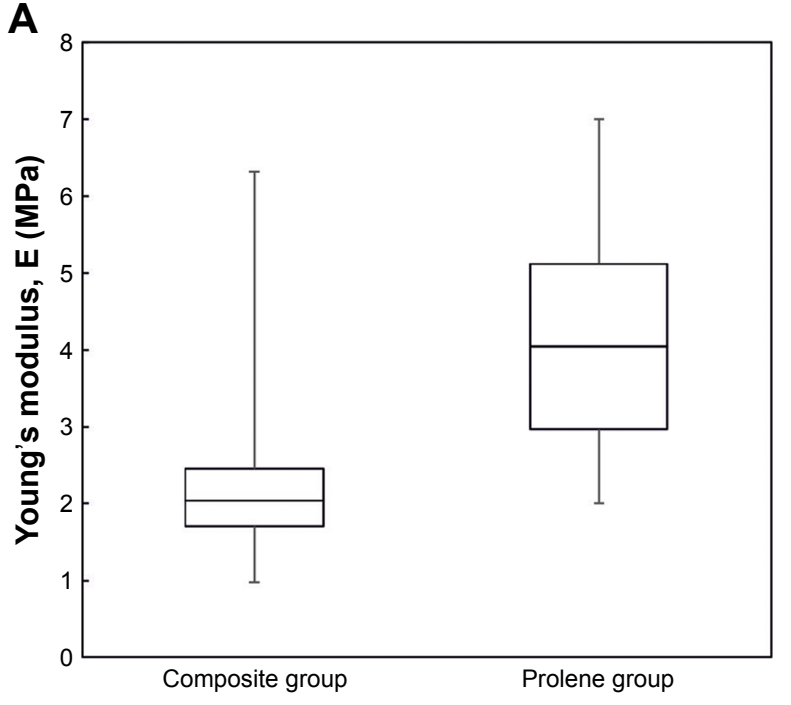

C

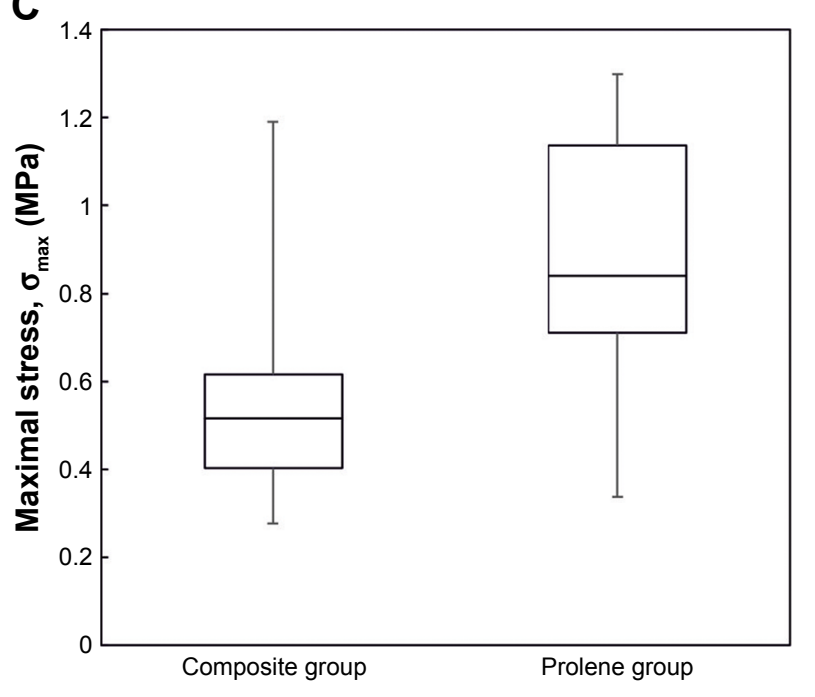

B

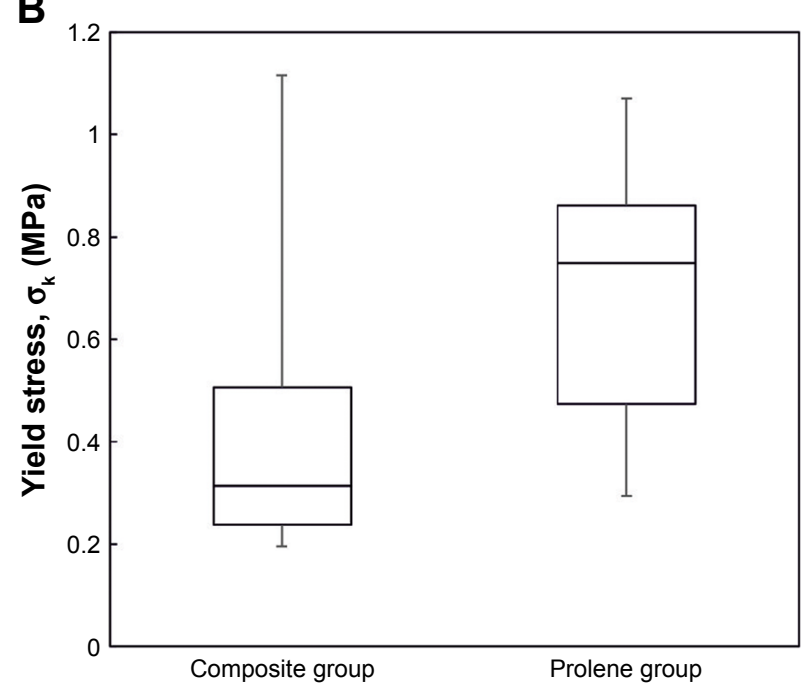

D

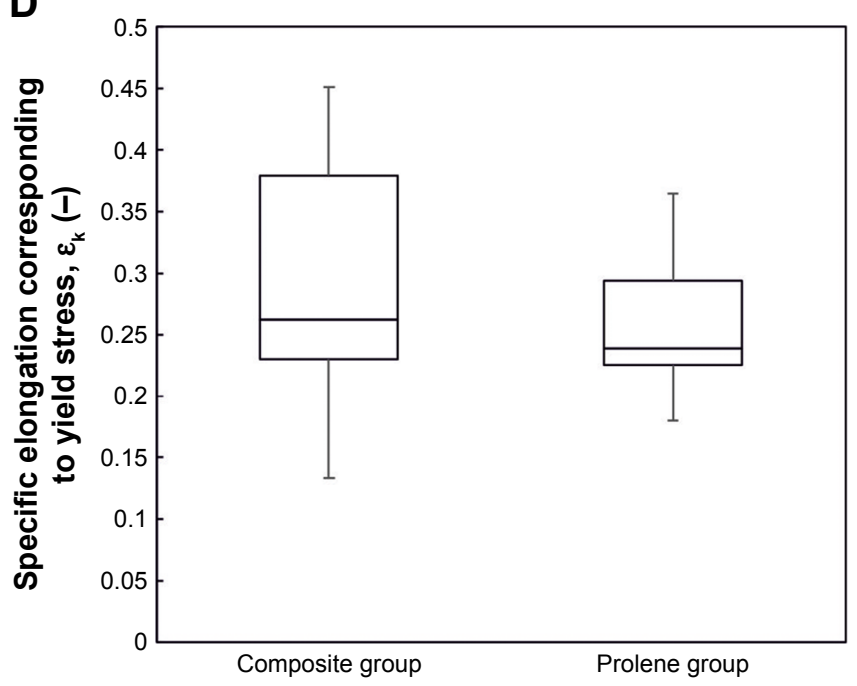

E

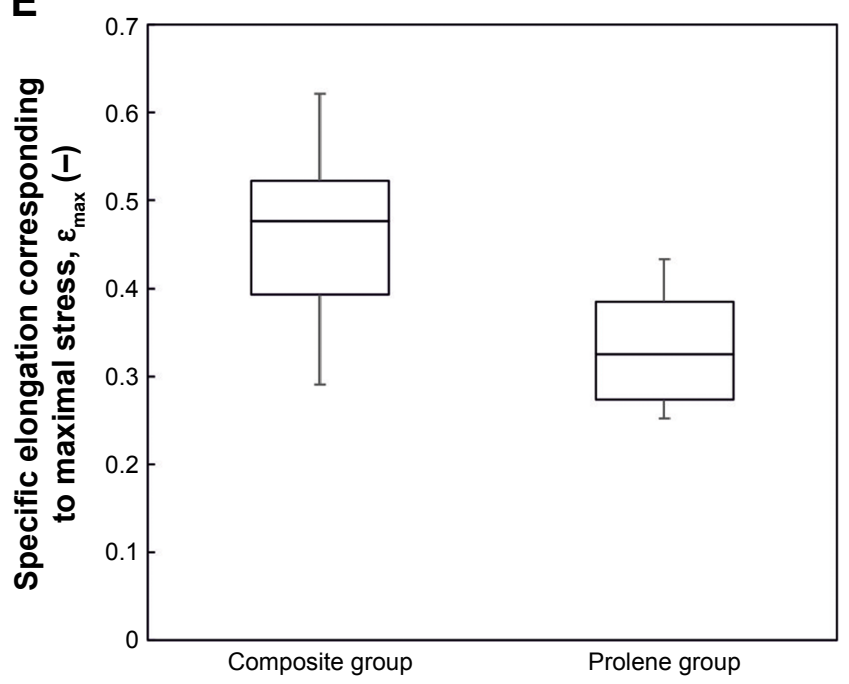

Figure 8 Comparison of monitored parameters of both groups, Composite vs Prolene groups.

Notes: A boxplot graph demonstrating the maximum and minimum measured values, first and third quartiles and median. (A) Elasticity; (B) yield stress; (C) maximal stress; (D) specific elongation corresponding to yield stress; and (E) specific elongation corresponding to maximal stress. 
by a chronic foreign body reaction. ${ }^{29} \mathrm{We}$ did not observe any significant differences in the amount of inflammatory infiltrate among the implants. Nowadays, more focus is being dedicated to the problem of mesh shrinkage and its effect on the biomechanics of the abdominal wall. ${ }^{30}$ Although the fraction of type I collagen in the incision area did not differ among the groups, a correlation analysis suggests that the maturation of type I collagen was associated with different histological patterns and remodeling process. In the Prolene group, greater relative amounts of mature type I collagen were accompanied with more actin-positive myofibroblasts and mature (actin-positive) blood vessels. However, in the Composite group, greater relative amount of type I collagen was found in regions with prominently greater densities of all microvessels including capillaries. The fibroblasts producing and controlling the maturation of type I collagen had a smaller tendency toward forming a contractile phenotype. Perhaps, this could lead to less shrinkage in the future in the Composite group.

Biomechanical analysis showed that the Composite material led to the formation of a scar that was less stiff and more elastic, but less resistant to distracting forces. Unfortunately, a similar experiment conducted by Melman et al used a different methodology. ${ }^{31}$ Samples were attached into the tension meter branches over the entire thickness of the abdominal wall, including the prosthetic material. We suggest that the attachment points should always be adjacent to the implanted material, so that the properties of the mesh-fascia interface and its resistance to distracting forces are tested. The parameters of the PP mesh are known, so we felt no need to test the implants alone. Another factor to consider is that we have conducted all of the biomechanical testing ex vivo and therefore with no active muscle activity. As the implant is the only nonliving, nonactive component of the tested sample, we can only speculate how would an active muscle tonus influence our results. On top of that, it is a known fact that the temperature influences mechanical properties of many synthetic and biological materials. Our measuring was conducted in a room temperature of $22^{\circ} \mathrm{C}$, which is not the natural temperature of an abdominal wall.

Interestingly, although the overall maximum tensile strength was lower in the Composite group, $\varepsilon_{\max }$ shows that samples in the Composite group $\left(\varepsilon_{\max }=0.476 \pm 0.088\right)$ can be stretched slightly more without being permanently damaged than the samples in the Prolene group $\left(\varepsilon_{\max }=0.325 \pm 0.057\right)$. However, due to the low number of samples, we could only use the SD of medians and quartiles, and the final results therefore do not reach the statistical significance.
Due to several changes in the production of the Composite material, we have observed slightly different results than in the previous experiment revealing how small adjustments in detail may play a big role in the final outcome when electrospun nanofibers are used. It would be interesting to see a longer experiment using such a material to evaluate its real clinical significance.

\section{Conclusion}

Based on the results of the histological examination, PCL nanofibers do exhibit positive effects on the healing of abdominal fascia when combined with a standard PP mesh. They lead to a more homogeneous distribution of type I collagen within the scar that is associated with a greater density of microvessels and not contractile myofibroblasts like in the Prolene group, which could indicate less shrinkage in the future, and therefore, more clinically favorable results.

However, the clinical outcome 6 weeks postimplantation was surprising, as the mesh was encapsulated in a thick fibrous plate less resistant than in the Prolene group. This fact could be explained by the large amount of glue used to combine the two materials or an ethylenoxide sterilization. Despite that, biomechanical testing showed that this scar was more elastic and got irreversibly damaged under higher tension, therefore exhibiting more favorable biomechanical properties.

\section{Acknowledgments}

The study was supported by the Ministry of Education, Youth and Sports of the Czech Republic within the National Sustainability Programme I (project numbers LO1605, LO1508, and LO1309), the Internal Grant Agency of the Ministry of Health of the Czech Republic (project numbers 16-29680A and 17-32285A), and the Czech Science Foundation (project number 15-15697S).

\section{Disclosure}

The authors report no conflicts of interest in this work.

\section{References}

1. Burger JW, Luijendijk RW, Hop WC, Halm JA, Verdaasdonk EG, Jeekel J. Long-term follow-up of a randomized controlled trial of suture versus mesh repair of incisional hernia. Ann Surg. 2004;240(4):578-583; discussion 583-585.

2. Flum DR, Horvath K, Koepsell T. Have outcomes of incisional hernia repair improved with time? A population-based analysis. Ann Surg. 2003; 237(1):129-135.

3. Elango S, Perumalsamy S, Ramachandran K, Vadodaria K. Mesh materials and hernia repair. Biomedicine (Taipei). 2017;7(3):16.

4. Baylón K, Rodríguez-Camarillo P, Elías-Zúñiga A, Díaz-Elizondo JA, Gilkerson R, Lozano K. Past, present and future of surgical meshes: a review. Membranes (Basel). 2017;7(3):E47. 
5. Zhu LM, Schuster P, Klinge U. Mesh implants: an overview of crucial mesh parameters. World J Gastrointest Surg. 2015;7(10):226-236.

6. Binnebösel M, von Trotha KT, Jansen PL, Conze J, Neumann UP, Junge $\mathrm{K}$. Biocompatibility of prosthetic meshes in abdominal surgery. Semin Immunopathol. 2011;33(3):235-243.

7. Agarwal S, Wendorff JH, Greiner A. Use of electrospinning technique for biomedical applications. Polymer. 2008;49(26):5603-5621.

8. Shankaran V, Weber DJ, Reed RL, Luchette FA. A review of available prosthetics for ventral hernia repair. Ann Surg. 2011;253(1):16-26.

9. Khil MS, Bhattarai SR, Kim HY, Kim SZ, Lee KH. Novel fabricated matrix via electrospinning for tissue engineering. J Biomed Mater Res B Appl Biomater. 2005;72(1):117-124.

10. Rampichova M, Chvojka J, Buzgo M, et al. Elastic three-dimensional poly (epsilon-caprolactone) nanofibre scaffold enhances migration, proliferation and osteogenic differentiation of mesenchymal stem cells. Cell Prolif. 2013;46(1):23-37.

11. Van Natta FJ, Hill JW, Carruthers WH. Polymerization and ring formation, -caprolactone and its polymers. J Am Chem Soc. 1934;56: 455-459.

12. Woodruff MA, Hutmacher DW. The return of a forgotten polymer polycaprolactone in the 21th century. Prog Polym Sci. 2010;35(10): 1217-1256.

13. Johnson J, Chakroff J, Kayuha D, Henderson M, et al. Development and characterization of novel electrospun meshes for hernia repair. SOJ Mater Sci Eng. 2015;2(2):1-9.

14. Ebersole GC, Buettmann EG, MacEwan MR, et al. Development of novel electrospun absorbable polycaprolactone (PCL) scaffolds for hernia repair applications. Surg Endosc. 2012;26(10):2717-2728.

15. Zhao W, Ju YM, Christ G, Atala A, Yoo JJ, Lee SJ. Diaphragmatic muscle reconstruction with an aligned electrospun poly( $\varepsilon$-caprolactone)/ collagen hybrid scaffold. Biomaterials. 2013;34(33):8235-8240.

16. Plencner M, East B, Tonar Z, et al. Abdominal closure reinforcement by using polypropylene mesh functionalized with poly- $\varepsilon$-caprolactone nanofibers and growth factors for prevention of incisional hernia formation. Int J Nanomed. 2014;9:3263-3277.

17. Whittaker P, Rich L. Collagen and picrosirius red staining: a polarized light assessment of fibrillar hue and spatial distribution. Braz $J$ Morphol Sci. 2005;22(2):97-104.

18. Tonar Z, Egger GF, Witter K, Wolfesberger B. Quantification of microvessels in canine lymph nodes. Microsc Res Tech. 2008;71(10): 760-772.

19. Zhang Y, Zhou Y, Zhou X, et al. Preparation of a nano- and micro-fibrous decellularized scaffold seeded with autologous mesenchymal stem cells for inguinal hernia repair. Int J Nanomedicine. 2017;12:1441-1452.
20. Holihan JL, Nguyen DH, Nguyen MT, Mo J, Kao LS, Liang MK. Mesh location in open ventral hernia repair: a systematic review and network meta-analysis. World J Surg. 2016;40(1):89-99.

21. Roman S, Mangir N, Bissoli J, Chapple CR, MacNeil S. Biodegradable scaffolds designed to mimic fascia-like properties for the treatment of pelvic organ prolapse and stress urinary incontinence. J Biomater Appl. 2016;30(10):1578-1588.

22. Zamani M, Prabhakaran MP, Ramakrishna S. Advances in drug delivery via electrospun and electrosprayed nanomaterials. Int $J$ Nanomed. 2013;8:2997-3017.

23. Bosworth LA, Downes S. Biocompatible three-dimensional scaffolds for tendon tissue engineering using electrospinning. In: Cellular Response to Biomaterials. Cambridge, UK: Woodhead Publishing Ltd; 2009:3-27.

24. Plencner M, Prosecká E, Rampichová M, et al. Significant improvement of biocompatibility of polypropylene mesh for incisional hernia repair by using poly- $\varepsilon$-caprolactone nanofibers functionalized with thrombocyte-rich solution. Int J Nanomed. 2015;10:2635-2646.

25. Hooper KA, Cox JD, Kohn J. Comparison of the effect of ethylene oxide and gamma-irradiation on selected tyrosine-derived polycarbonates and poly(L-lactic acid). J Appl Polym Sci. 1997;63(11):1499-1510.

26. Vogels RR, van Barneveld KW, Bosmans JW, et al. Long-term evaluation of adhesion formation and foreign body response to three new meshes. Surg Endosc. 2015;29(8):2251-2259.

27. Kahan LG, Lake SP, McAllister JM, et al. Combined in vivo and ex vivo analysis of mesh mechanics in a porcine hernia model. Surg Endosc. 2018;32(2):820-830.

28. Deeken CR, Abdo MS, Frisella MM, Matthews BD. Physicomechanical evaluation of absorbable and nonabsorbable barrier composite meshes for laparoscopic ventral hernia repair. Surg Endosc. 2011;25(5): 1541-1552.

29. Dai Z, Ronholm J, Tian Y, Sethi B, Cao X. Sterilization techniques for biodegradable scaffolds in tissue engineering applications. J Tissue Eng. 2016;7:2041731416648810.

30. Vink P, Pleijsier K. Aeration of ethylene oxide-sterilized polymers. Biomaterials. 1986;7(3):225-230.

31. Melman L, Jenkins ED, Hamilton NA, et al. Histologic and biomechanical evaluation of a novel macroporous polytetrafluoroethylene knit mesh compared to lightweight and heavyweight polypropylene mesh in a porcine model of ventral incisional hernia repair. Hernia. 2011; 15(4):423-431.

32. Lukas D, Sarkar A, Martinova L, et al. Physical principles of electrospinning (electrospinning as a nano-scale technology of the twenty-first century). Text Prog. 2009;41(2):59-140. 


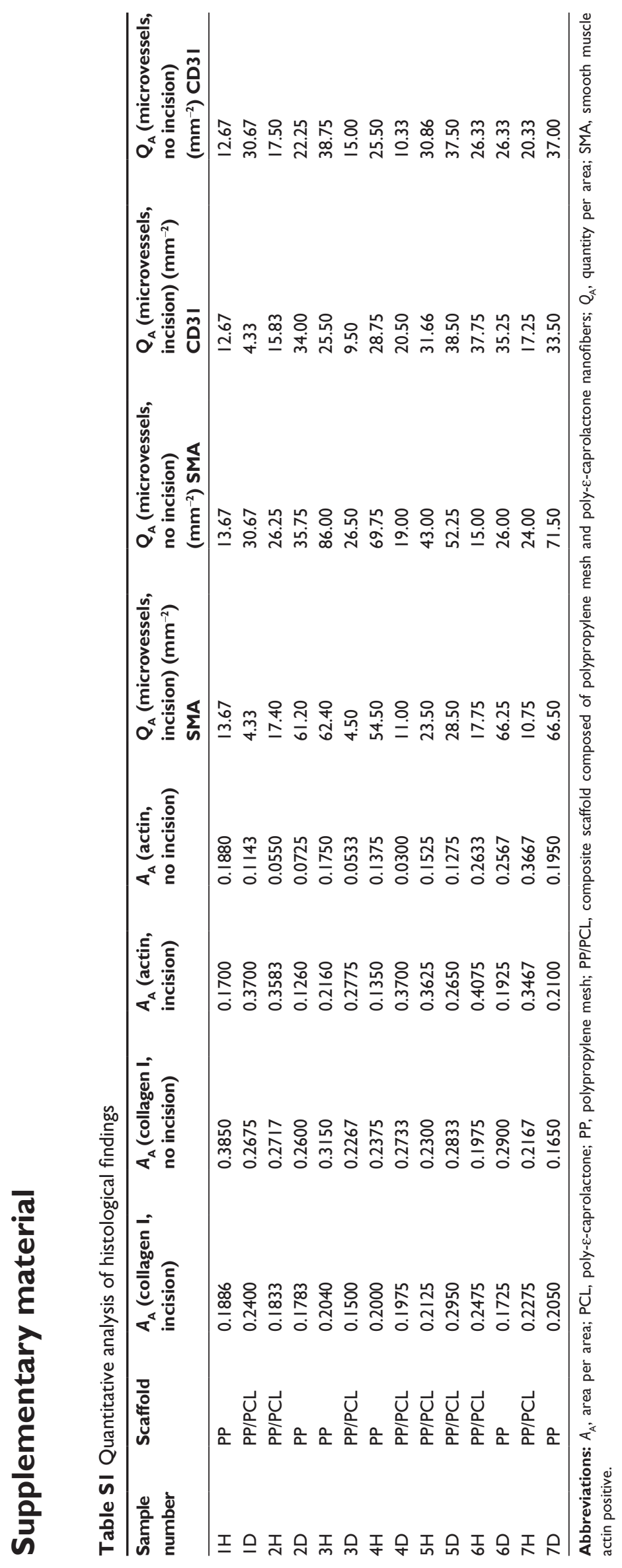


International Journal of Nanomedicine

Dovepress

\section{Publish your work in this journal}

The International Journal of Nanomedicine is an international, peerreviewed journal focusing on the application of nanotechnology in diagnostics, therapeutics, and drug delivery systems throughout the biomedical field. This journal is indexed on PubMed Central, MedLine, CAS, SciSearch ${ }^{\circledR}$, Current Contents ${ }^{\circledR} /$ Clinical Medicine,
Journal Citation Reports/Science Edition, EMBase, Scopus and the Elsevier Bibliographic databases. The manuscript management system is completely online and includes a very quick and fair peer-review system, which is all easy to use. Visit http://www.dovepress.com/ testimonials.php to read real quotes from published authors.

Submit your manuscript here: http://www.dovepress.com/international-journal-of-nanomedicine-journal 